\title{
Wearing a full metal jacket should not be en vogue
}

\author{
Tom C. Nguyen, MD, and Konstantinos Charitakis, MD
}

\author{
From the Department of Cardiothoracic Surgery, University of Texas Houston-Memorial Hermann, Houston, \\ Tex \\ Disclosures: Authors have nothing to disclose with regard to commercial support. \\ Received for publication Aug 14, 2017; accepted for publication Aug 25, 2017; available ahead of print Sept 22, \\ 2017. \\ Address for reprints: Tom C. Nguyen, MD, Department of Cardiothoracic Surgery, University of Texas Houston- \\ Memorial Hermann, 6400 Fannin, Suite 2850, Houston, TX 77030 (E-mail: tom.c.nguyen@ gmail.com). \\ J Thorac Cardiovasc Surg 2018;155:227-8 \\ $0022-5223 / \$ 36.00$ \\ Copyright (c) 2017 by The American Association for Thoracic Surgery \\ http://dx.doi.org/10.1016/j.jtcvs.2017.08.072
}

Coronary artery aneurysm, defined as a luminal dilation $50 \%$ larger than that of the adjacent reference segment, is a rare finding. After a percutaneous coronary intervention, the proposed mechanism is arterial wall injury caused either by balloon inflation, atherectomy, or oversized stent placement. The presence of antiproliferative drug in a drug-eluting stent may involve additional mechanisms, such as delayed reendothelialization, inflammatory changes of the medial wall, and hypersensitivity reactions. ${ }^{1-5}$ Systemic administration of anti-inflammatory agents (glucocorticoids and colchicine) after bare-metal stent implantation has also been associated with a greater risk of aneurysm formation. ${ }^{6}$ They are usually detected at the time of repeat angiography for recurrent symptoms or abnormal stress test results, but very rarely they may present with rupture, stent thrombosis, or distal vessel embolism. Because of the rarity of these events, however, the natural history, prognosis, and optimal treatment of coronary artery aneurysms after stent implantation remain unknown.

In this issue of the Journal, Ohira and colleagues ${ }^{7}$ describe a rare case of a proximal left anterior descending (LAD) coronary artery aneurysm formation that was detected 16 years after extensive stenting of the LAD artery with multiple bare-metal stents-full metal jacket. The patient presented with angina, with coronary angiography revealing a markedly stenotic false lumen as an inflow to the true coronary aneurysm and distal LAD. Because of persistent symptoms, the patient underwent coronary artery aneurysm resection, stent removal with endarterectomy, and onlay patch grafting of the LAD.

Although there are no clear guidelines on the management of coronary aneurysms, the combination of aneurysm size, expansion history, and symptoms guides the treatment. Some aneurysms resolve naturally, but others can lead to life-threatening complications from stent restenosis or thrombosis, so the management should be individually tailored. Diagnostic modalities such as intravascular ultrasound, optical coherence tomography, computed tomographic angiography, and magnetic resonance imaging can give further anatomic insights,

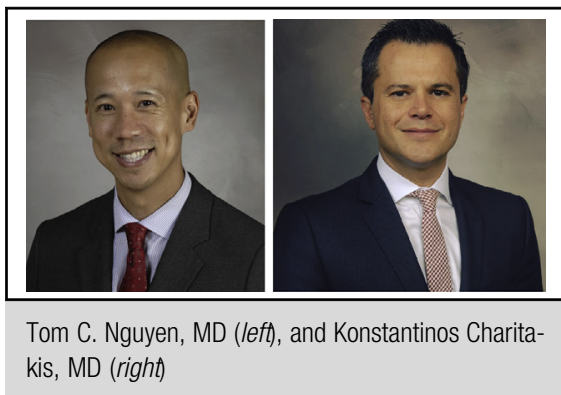

Central Message

Coronary artery aneurysm is a potential complication after extensive placement of bare metal stents, and it can potentially be avoided by coronary artery bypass grafting.

See Article page 225.

including possible stent malapposition, which seems to have major prognostic implications, and should be used to guide the optimal treatment approach. ${ }^{8}$ In this case, and given that the false lumen was the only inflow to the aneurysm and the LAD, the surgical approach was the appropriate treatment option.

This interesting case report highlights a potential approach for treating a stenotic false lumen as inflow into a coronary aneurysm after full metal jacket, but should also provide caution regarding aggressive baremetal stenting and its potential sequelae. The incidence of coronary aneurysm after percutaneous coronary intervention can be as high as 6\% in some series, but it is nearly nonexistent after coronary artery bypass grafting. At the age of 75 , this patient ultimately received a left internal thoracic artery graft to the LAD, but perhaps this complication could have been avoided all together had coronary artery bypass grafting been the initial therapeutic approach. In an era in which full metal jackets are increasingly en vogue, as argued by Lee and associates 9 and by Banarjee and colleagues, ${ }^{10}$ we would argue against jumping on the trends of the time until the evolution and maturation of more data.

\section{References}

1. Bell MR, Garratt KN, Bresnahan JF, Edwards WD, Holmes DR Jr. Relation of deep arterial resection and coronary artery aneurysms after directional coronary atherectomy. J Am Coll Cardiol. 1992;20:1474-81.

2. Baumbach A, Bittl JA, Fleck E, Geschwind HJ, Sanborn TA, Tcheng JE, et al. Acute complications of excimer laser coronary angioplasty: a detailed analysis of multicenter results. Coinvestigators of the U.S. and European Percutaneous Excimer Laser Coronary Angioplasty (PELCA) Registries. J Am Coll Cardiol. 1994;23:1305-13. 
3. Slota PA, Fischman DL, Savage MP, Rake R, Goldberg S. Frequency and outcome of development of coronary artery aneurysm after intra-coronary stent placement and angioplasty. STRESS Trial Investigators. Am J Cardiol. 1997;79:1104-6.

4. Condado JA, Waksman R, Gurdiel O, Espinosa R, Gonzalez J, Burger B, et al Long-term angiographic and clinical outcome after percutaneous transluminal coronary angioplasty and intracoronary radiation therapy in humans. Circulation. 1997;96:727-32.

5. Virmani R, Liistro F, Stankovic G, Di Mario C, Montorfano M, Farb A, et al. Mechanism of late in-stent restenosis after implantation of a paclitaxel derivate-eluting polymer stent system in humans. Circulation. 2002;106: 2649-51.

6. Rab ST, King SB III, Roubin GS, Carlin S, Hearn JA, Douglas JS Jr Coronary aneurysms after stent placement: a suggestion of altered vessel wall healing in the presence of anti-inflammatory agents. J Am Coll Cardiol. 1991; 18:1524-8.

7. Ohira S, Yaku H, Takanashi S. Stenotic false lumen as inflow of coronary aneurysm and full-metal jacket. J Thorac Cardiovasc Surg. 2018;155:225-6.

8. Alfonso F, Pérez-Vizcayno MJ, Ruiz M, Suárez A, Cazares M, Hernández R, et al. Coronary aneurysms after drug-eluting stent implantation: clinical, angiographic, and intravascular ultrasound findings. J Am Coll Cardiol. 2009; 53:2053-60.

9. Lee PH, Lee SW, Yun SC, Bae J, Anh JM, Park DW, et al. Full metal jacket with drug-eluting stents for coronary chronic total occlusion. JACC Cardiovasc Interv. 2017; 10:1405-12.

10. Banarjee S, Brilakis ES. Full metal jacket: Is it en vogue? JACC Cardiovasc Interv. 2017;10:1413-4. 